\title{
RGD peptide-modified multifunctional dendrimer platform for drug encapsulation and targeted inhibition of cancer cells
}

Xuedan He, ${ }^{\mathrm{a}}$ Carla S. Alves, ${ }^{\mathrm{a}}$ Nilsa Oliveira, ${ }^{\mathrm{a}}$ João Rodrigues, ${ }^{\mathrm{a}}$ Jingyi Zhu, ${ }^{\mathrm{b}}$ István Bányai, ${ }^{* \mathrm{c}}$ Helena Tomás, ${ }^{\text {a }}$ Xiangyang Shi ${ }^{\text {a,b }}$

${ }^{a}$ CQM-Centro de Química da Madeira, Universidade da Madeira, Campus da Penteada, 9000-390 Funchal, Portugal

${ }^{b}$ State Key Laboratory for Modification of Chemical Fibers and Polymer Materials, College of Materials Science and Engineering, Donghua University, Shanghai 201620, People's Republic of China

${ }^{c}$ Department of Colloid and Environmental Chemistry, Faculty of Science, University of Debrecen, H4032 Egyetem t.1, Debrecen, Hungary

* Corresponding author. E-mail addresses: xshi@dhu.edu.cn (X. Shi), lenat@uma.pt (H. Tomás), ibanyai@delfin.klte.hu (I. Bányai) 


\begin{abstract}
:
Development of multifunctional nanoscale drug delivery systems for targeted cancer therapy still remains a great challenge. Here we report the synthesis of cyclic arginine-glycine-aspartic acid (RGD) peptide-conjugated generation 5 (G5) poly(amidoamine) dendrimers for anticancer drug encapsulation and targeted therapy of cancer cells overexpressing $\alpha_{v} \beta_{3}$ integrins. In this study, amine-terminated G5 dendrimers were used as a platform to be sequentially modified with fluorescein isothiocyanate (FI) via a thiourea linkage and RGD peptide via a polyethylene glycol (PEG) spacer, followed by acetylation of the remaining dendrimer terminal amines. The developed multifunctional dendrimer platform (G5.NHAc-FI-PEG-RGD) was then used to encapsulate an anticancer drug doxorubicin (DOX). We show that approximately 6 DOX molecules are able to be encapsulated within each dendrimer platform. The formed complexes are water soluble, stable, and able to release DOX in a sustained manner. One-dimensional and two-dimensional NMR techniques were applied to investigate the interaction between dendrimers and DOX, and the impact of the environmental $\mathrm{pH}$ on the release rate of DOX from the dendrimer/DOX complexes was also explored. Furthermore, cell biological studies demonstrate that the encapsulation of DOX within the G5.NHAc-FI-PEG-RGD dendrimers does not compromise the anticancer activity of DOX, and that the therapeutic efficacy of the dendrimer/DOX complexes is solely related to the encapsulated DOX drug. Importantly, thanks to the role played by RGD-mediated targeting, the developed dendrimer/drug complexes are able to specifically target $\alpha_{v} \beta_{3}$ integrin-overexpressing cancer cells and display specific therapeutic efficacy to the target cells. The developed RGD peptide-targeted multifunctional dendrimers may thus be used as a versatile platform for targeted therapy of different types of $\alpha_{\nu} \beta_{3}$ integrin-overexpressing cancer cells.
\end{abstract}

Keywords: dendrimers; RGD peptide; doxorubicin; host-guest interaction; targeted cancer therapy. 


\section{Introduction}

The past decades have seen an increasing interest in the use of various nanoparticulate systems for therapeutics (drug and gene delivery) [1-6], diagnostics [7-10], and the combination of both therapeutics and diagnostics (theranostics) [11-13]. In particular, the use of nanoparticles (NPs) as a drug carrier is able to overcome some of the current drawbacks of conventional cancer chemotherapy by improving the water solubility and thus the bioavailability of the drug, by improving the specificity of the drug via either enhanced permeability and retention (EPR)-based passive targeting [14] or active targeting pathway through ligand-receptor interaction [12, 15-17], and by facilitating a controlled release of the drug [18-21].

Among the many investigated nanoscale drug delivery systems, dendrimers, a class of highly branched, monodispersed, and synthetic macromolecules with well-defined structure and composition [22, 23], have received a myriad of interest. Dendrimers are sufficiently small in size (e.g., the diameter of a generation 5 (G5) poly(amidoamine) (PAMAM) dendrimer is $5.4 \mathrm{~nm}$ ), rendering them with the ability to pass through the renal filter [1], thereby eliminating the need for them to be biodegradable. The surface of dendrimers can be covalently modified with targeting ligands, imaging agents, and anticancer drugs for simultaneous targeting, imaging, and therapeutic treatment of cancer cells [23-27]. Alternatively, the internal cavities of dendrimers can be used as a host to encapsulate guest molecules $[2,3,28,29]$. In addition, the terminal groups of dendrimers can also be modulated to avoid issues of toxicity and nonspecific cell membrane binding. For example, acetylation [8, 30-32] and carboxylation [33] of dendrimers with amine termini can significantly improve the biocompatibility of dendrimers. Besides, full or partial PEGylation (PEG refers to 
poly(ethylene glycol)) of dendrimers can effectively prolong their blood stream circulation and also improve their biocompatibility [9, 34-37].

Doxorubicin (DOX) is an anticancer drug widely used in the treatment of hematological malignancies, many types of carcinoma, and soft tissue sarcomas [38-40]. Similar to other conventional anticancer drugs, free DOX is water-insoluble, cytotoxic to normal cells or tissues, and can be easily cleared by the blood stream [2], thereby limiting its clinical applications. As a consequence, it may be advantageous to use dendrimers as DOX carriers [41]. It has been shown that DOX can be either encapsulated within dendrimers via physical encapsulation/complexation [2, 42] or conjugated onto the surface of dendrimers via a covalent linkage [43-46]. Each method has its own advantages and drawbacks. For instance, the former approach is relatively simple but the stability of the dendrimer/drug complexes in vivo could be a challenging issue [47, 48]. The latter approach involves a covalent attachment of the drug onto the dendrimer surface, which offers stable dendrimer-drug conjugates. However, the conjugation process usually requires multi-step organic reactions and the linkage has to be carefully chosen since the drug molecules have to be cleaved and released under specific biological conditions [25, 49].

Recently, we have shown that G5 PAMAM dendrimers (with acetyl termini) covalently linked with fluorescein isothiocyanate (FI) and folic acid (FA) are able to physically encapsulate DOX for targeted delivery to cancer cells overexpressing FA receptors [2]. In our another study, we demonstrated the use of ${ }^{1} \mathrm{H}$ NMR, two-dimensional (2D) nuclear Overhauser enhancement spectroscopy (NOESY), and diffusion-ordered spectroscopy (DOSY) techniques to investigate the host-guest interactions of dendrimer/DOX complexes in order to delineate the drug release mechanism [42]. With the ability of dendrimers to be covalently linked with other targeting ligands 
such as hyaluronic acid [50], monoclonal antibodies [51], and peptides [52, 53], it is logical to design multifunctional dendrimer-based drug delivery systems modified with other types of targeting ligands. In particular, as one of the most studied ligands, arginine-glycine-aspartic acid (RGD) peptide has been conjugated onto the surface of dendrimers to target $\alpha_{\nu} \beta_{3}$ integrin-overexpressing cancer cells $[54,55]$. Although DOX has been covalently linked to the surface of RGD-modified PAMAM dendrimer conjugate via an acid-sensitive cis-aconityl linkage for targeted therapy of murine B16 melanoma [56], few studies are related to the use of RGD-conjugated dendrimers as a platform to physically encapsulate DOX for targeted cancer therapy applications. In addition, the use of advanced NMR techniques to explore the host-guest interaction between RGD-conjugated dendrimers and DOX has not been reported in the literature.

In this present study, we synthesized a multifunctional G5 dendrimer platform by sequential modification of FI and PEGylated RGD, followed by acetylation of the remaining dendrimer terminal amines to form multifunctional G5.NHAc-FI-PEG-RGD dendrimers. The formed dendrimer platform was used to physically encapsulate DOX (Figure 1). The encapsulation efficiency, release kinetics, and targeted inhibition of integrin $\alpha_{\nu} \beta_{3}$-overexpressing cancer cells were systematically investigated. The host-guest interactions of the G5.NHAc-FI-PEG-RGD/DOX complexes were investigated by multiple NMR techniques in order to delineate the release mechanism of the encapsulated DOX. To our knowledge, this is the first report related to the use of multifunctional RGD-modified G5 dendrimers as a platform to physically encapsulate DOX for targeted cancer therapy applications.

\section{Results and discussion}




\subsection{Synthesis and characterization of the G5.NHAc-FI-PEG-RGD dendrimers}

G5 PAMAM dendrimers were selected for the synthesis of multifunctional drug carriers due to their relative small size $(5.4 \mathrm{~nm}$, comparable to hemoglobin) and numerous terminal amine groups that can be modified with different functionalities $[57,58]$. To enable the dendrimer carrier to be tracked within the cells via fluorescence microscopy, FI was covalently attached to the dendrimer surface. Then, the FI-modified dendrimers were covalently attached with RGD peptide via a PEG spacer to target cancer cells overexpressing integrin $\alpha_{\mathrm{v}} \beta_{3}$ [59]. The used PEG spacer is crucial to improve the targeting specificity of ligand-functionalized dendrimers to cancer cells [60, 61]. Finally, the remaining dendrimer terminal amines were acetylated not only to improve the biocompatibility of the dendrimers, but also to minimize their non-specific binding to cell membranes. The overall synthesis process is illustrated in Figure 1.

The chemical structure of each dendrimer product and intermediate was characterized by ${ }^{1} \mathrm{H}$ NMR spectroscopy. The G5 dendrimer was first linked with FI via a thiourea linkage to form the G5. $\mathrm{NH}_{2}$-FI conjugate, which was confirmed by the appearance of a characteristic peak at $3.75 \mathrm{ppm}$ in the ${ }^{1} \mathrm{H}$ NMR spectrum (Figure S1, Supporting Information). By comparison of the NMR integration of the aromatic proton peaks at 6.5 and $7.1 \mathrm{ppm}$ for FI and the methylene protons of the G5 dendrimer, the number of FI moieties attached onto each dendrimer was estimated to be 10.0. Before covalently linking the RGD moieties onto the dendrimer surface, PEGylated RGD with the other end of carboxyl group was synthesized. Through the NMR integration of the RGD-associated aromatic proton peaks at 7.3 and $7.4 \mathrm{ppm}$ and the PEG methylene proton at $3.7 \mathrm{ppm}$ (Figure S2, Supporting Information), the number of RGD moieties linked to each PEG molecule was estimated to be 0.3 . 
The PEGylated RGD was then conjugated onto the surface of the G5. $\mathrm{NH}_{2}$-FI dendrimer, followed by acetylation of the remaining dendrimer terminal amines. Figure 2 shows the ${ }^{1} \mathrm{H}$ NMR spectrum and peak assignments of the final G5.NHAc-FI-PEG-RGD conjugate. The characteristic PEG methylene proton peak at $3.6 \mathrm{ppm}$, the overlapped proton signals in the aromatic region for both FI and the phenyl ring of RGD, and the overlapped aliphatic proton signals of the dendrimer and the RGD peptide can be clearly seen. After the final acetylation step, a new peak at $1.87 \mathrm{ppm}$ was detected in the ${ }^{1} \mathrm{H}$ NMR spectrum, which can be assigned to the $-\mathrm{CH}_{3}$ protons of the acetyl groups. The emergence of this peak is indicative of the conversion of the remaining dendrimer terminal amines to acetamides, in agreement with the data in the literature [3]. Based on the integration of the relevant peaks in the ${ }^{1} \mathrm{H}$ NMR spectrum in Figure 2, the number of HOOC-PEG-RGD attached onto each G5 dendrimer was estimated to be 12.0. Consequently, the practical number of RGD peptides attached onto each G5 dendrimer was calculated to be 4.0. According to the literature [62], 2-3 RGD peptides attached onto each dendrimer are sufficient to effectively target cancer cells via ligand-receptor interaction.

UV-vis spectroscopy was also used to characterize the synthesized G5.NHAc-FI-PEG-RGD conjugate (Figure S3, Supporting Information). For comparison, UV-vis spectra of HOOC-PEG-RGD and G5.NH 2 -FI were also included. HOOC-PEG-RGD shows a characteristic shoulder at around $275 \mathrm{~nm}$, in agreement with the literature [62]. In contrast to the $\mathrm{G}_{5} \cdot \mathrm{NH}_{2}-\mathrm{FI}$ conjugate that just shows a characteristic FI-associated peak at $500 \mathrm{~nm}$, the G5.NHAc-FI-PEG-RGD conjugate displays absorption features related to both FI absorption at $500 \mathrm{~nm}$ and RGD absorption at around $275 \mathrm{~nm}$.

\subsection{Encapsulation of DOX within the G5.NHAc-FI-PEG-RGD dendrimers}


The neutralization of $\mathrm{DOX} \cdot \mathrm{HCl}$ to form hydrophobic DOX rendered it to be efficiently encapsulated within the relatively hydrophobic interior of the G5.NHAc-FI-PEG-RGD dendrimers. The formed G5.NHAc-FI-PEG-RGD/DOX complexes were characterized by UV-vis spectroscopy (Figure 3). The UV-vis spectra of free DOX dissolved in ethanol and the DOX-free G5.NHAc-FI-PEG-RGD dendrimers were also recorded for comparison. It is clear that free DOX shows a strong absorption peak at $481 \mathrm{~nm}$. After DOX encapsulation, the G5.NHAc-FI-PEG-RGD/DOX complexes have an absorption enhancement at $481 \mathrm{~nm}$ when compared with the G5.NHAc-FI-PEG-RGD dendrimers without DOX under a similar dendrimer concentration. This indicates that DOX has been successfully encapsulated within the G5.NHAc-FI-PEG-RGD dendrimers. The number of DOX molecules encapsulated within each G5.NHAc-FI-PEG-RGD conjugate was measured to be 6.0 via $\mathrm{UV}$-vis spectroscopy, which is larger than that encapsulated within each acetylated G5 dendrimer modified with FA and FI as reported in our previous work [2]. This may be due to the fact that the hydrophilic PEG chains used in this study to prepare the G5.NHAc-FI-PEG-RGD dendrimers induce less steric hindrance than the relatively hydrophobic FA moieties directly attached onto the dendrimer surface [36].

The stability of the G5.NHAc-FI-PEG-RGD/DOX complexes is very important for their biological applications. As can be seen in Figure S4 (Supporting Information), the lyophilized powders of the G5.NHAc-FI-PEG-RGD dendrimers without DOX and the G5.NHAc-FI-PEG-RGD/DOX complexes could be dissolved in aqueous solution under different $\mathrm{pH}$ conditions $(\mathrm{pH}=5.0,7.0$, and 10.0, respectively). The dispersions remained stable and no precipitation occurred when stored for at least two months at room temperature. Likewise, the stability of the complexes was also tested by exposing them to cell culture medium containing $10 \%$ 
of fetal bovine serum. We showed that the G5.NHAc-FI-PEG-RGD/DOX complexes were quite stable and no precipitation occurred when the complexes were stored at $4{ }^{\circ} \mathrm{C}$ for at least one week. The zeta potentials of the G5.NHAc-FI-PEG-RGD dendrimers and the G5.NHAc-FI-PEG-RGD/DOX complexes at different $\mathrm{pH}$ conditions are listed in Table S1 (Supporting Information). The larger values at $\mathrm{pH} 5.0$ for both the dendrimers and the complexes than those at other $\mathrm{pHs}$ suggests that a portion of the dendrimer tertiary amines are protonated at $\mathrm{pH}$ 5.0 [63]. The change in the surface potentials of both the dendrimers and the complexes with $\mathrm{pH}$ followed the same trend as that of the G5.NHAc dendrimers described in our previous work [48].

\subsection{In vitro release kinetic studies}

To exert its anticancer therapeutic efficacy, the DOX encapsulated within the G5.NHAc-FI-PEG-RGD/DOX complexes should be released. As such, the in vitro DOX release kinetics of the complexes was explored in either PBS $(\mathrm{pH}=7.4)$ or acetate buffer $(\mathrm{pH}=5.0)$ media at $37^{\circ} \mathrm{C}$ (Figure 4). For comparative purposes, the release kinetics of free DOX dissolved in ethanol was also evaluated. In the latter case, it was found that $80 \%$ DOX was released within just $2 \mathrm{~h}$. In contrast, DOX was released from the G5.NHAc-FI-PEG-RGD/DOX complexes in a sustained manner under both $\mathrm{pH}$ conditions. Moreover, the release of DOX from the complexes followed a biphasic profile, in which an initial fast release phase followed by a sustained release phase was detected (Figure 4). In acetate buffer $(\mathrm{pH} 5.0$ ), about $10 \%$ and $21 \%$ of the drug was released from the complexes within $1 \mathrm{~h}$ and $24 \mathrm{~h}$, respectively. In comparison, the drug release rate in PBS (pH 7.4) was found to be faster with about $35 \%$ and $57 \%$ of the DOX being released from the complex within $1 \mathrm{~h}$ and $24 \mathrm{~h}$, respectively. The prolonged release profile of DOX from the complexes under the two different $\mathrm{pH}$ conditions implies that the dendrimer interiors are powerful for effective retention of 
the DOX drug. The higher release rate of DOX from the complexes at $\mathrm{pH} 7.4$ than at $\mathrm{pH} 5.0$ could be due to the fact that under acidic $\mathrm{pH}$ conditions, the protonated DOX molecules are unlikely able to form strong hydrogen bonding with the dendrimer terminal functional groups (deprotonated amines and terminal polar C-O-C bonds of the PEG moieties), leading to a slower release of DOX. In contrast, under slightly basic conditions at $\mathrm{pH} 7.4$, the DOX molecules are able to be partially deprotonated and to form strong hydrogen bonding with the dendrimer terminal functional groups, resulting in a faster release rate of the drug from the dendrimer interior, in agreement with our previous work [36].

\subsection{Host-guest interactions of the dendrimer/DOX complexes}

To better understand the in vitro drug release mechanism under different $\mathrm{pH}$ conditions, NMR techniques have been used to investigate the host-guest interaction between DOX molecules and the dendrimer platform [64]. The influence of the $\mathrm{pH}$ on the interaction between the G5.NHAc-FI-PEG-RGD dendrimer and $\mathrm{DOX} \cdot \mathrm{HCl}$ in $\mathrm{D}_{2} \mathrm{O}$ was first investigated via $1 \mathrm{D}{ }^{1} \mathrm{H}$ NMR experiments (Figure 5). When compared with the ${ }^{1} \mathrm{H}$ NMR spectrum of G5.NHAc-FI-PEG-RGD/DOX complex at pH 7.0 (Figure 5b), an increase in the chemical shift in the peaks corresponding to the dendrimer methylene protons $(c, e)$ was detected in the spectrum of G5.NHAc-FI-PEG-RGD/DOX at pH 5.0 (Figure 5a). This increase in the chemical shift of the adjacent $-\mathrm{CH}_{2}$ - groups in G5.NHAc-FI-PEG-RGD/DOX at $\mathrm{pH} 5.0$ can be attributed to the fact that about $70 \%$ of the tertiary amine groups in G5 dendrimers are protonated at $\mathrm{pH} 5.0$ relative to all tertiary amine groups in G5 dendrimers being deprotonated at $\mathrm{pH} 7.0$ [65]. Moreover, compared

with the ${ }^{1} \mathrm{H}$ NMR spectrum of DOX $\cdot \mathrm{HCl}$ (Figure $5 \mathrm{c}$ ), the peaks of DOX protons show obvious changes after mixing with the G5.NHAc-FI-PEG-RGD dendrimer in both acidic and neutral 
circumstances, suggesting that intermolecular interactions occur between the dendrimer host and the DOX guest. In addition, at $\mathrm{pH}$ 5.0, line broadening of the DOX proton signals was observed. This line broadening can be attributed to the decreased degree of freedom of the bound DOX molecules, thereby indicating an increased ratio of coordinated DOX within the G5.NHAc-FI-PEG-RGD dendrimers. The interaction between G5.NHAc-FI-PEG-RGD and DOX was further investigated by 2D-NOESY (Figure S5, Supporting Information) and DOSY experiments. Details can also be seen in the Supporting Information.

\subsection{Therapeutic efficacy of DOX encapsulated within the G5.NHAc-FI-PEG-RGD dendrimers}

The therapeutic efficacy of the DOX complexed with G5.NHAc-FI-PEG-RGD dendrimers was tested via MTT viability assay of U87MG cells (Figure 6). After incubation of the cells with the dendrimer/DOX complexes for $48 \mathrm{~h}$, both free $\mathrm{DOX} \cdot \mathrm{HCl} \quad(5 \mu \mu)$ and the G5.NHAc-FI-PEG-RGD/DOX complexes with DOX concentration of $5 \mu \mathrm{M}$ are able to cause a significant loss of the cell viability when compared with the control cells treated with PBS (p < 0.001). To exclude the possible inherent toxicity of the dendrimers, the multifunctional G5.NHAc-FI-PEG-RGD dendrimers without DOX were also tested at an equivalent dendrimer concentration. It is clear that the G5.NHAc-FI-PEG-RGD dendrimers are non-toxic $(\mathrm{p}>0.05)$. These results indicate that the encapsulation of DOX within the G5 dendrimers does not compromise the therapeutic activity of the drug, and that the anticancer activity of the G5.NHAc-FI-PEG-RGD/DOX complexes is solely related to the complexed DOX drug.

The anticancer effect of the G5.NHAc-FI-PEG-RGD/DOX complexes was further confirmed by microscopic visualization of the morphology of cells treated with the complexes (Figure S6, 
Supporting Information). It can be seen that similar to the treatment with free DOX $\cdot \mathrm{HCl}$ (Figure S6c), cells treated with the G5.NHAc-FI-PEG-RGD/DOX complexes at the same DOX concentration $(5 \mu \mathrm{M})$ display comparable cell morphological changes (Figure S6d). A significant portion of the cells became rounded and non-adherent, indicative of cell death. In contrast, no rounded and detached cells can be visualized in control cells without DOX treatment (Figure S6a), cells treated with $10 \mu \mathrm{L}$ PBS (Figure S6b), and cells treated with the G5.NHAc-FI-PEG-RGD dendrimers without DOX but with a similar dendrimer concentration to that of the complexes (Figure S6e). This further suggests that the anticancer activity of the G5.NHAc-FI-PEG-RGD/DOX complexes is solely related to the complexed DOX drug, corroborating the MTT assay results.

\subsection{Targeted inhibition of cancer cells using the G5.NHAc-FI-PEG-RGD/DOX complexes}

The cyclic RGD peptide was selected as a targeting ligand to be conjugated onto the dendrimer surface to achieve the specific delivery of DOX to cancer cells overexpressing $\alpha_{v} \beta_{3}$ integrins. U87MG cells overexpressing $\alpha_{v} \beta_{3}$ integrins were selected to be treated with the G5.NHAc-FI-PEG-RGD/DOX complexes. For comparison, U87MG cells treated with free RGD (2 $\mu \mathrm{M}$ ) for $1 \mathrm{~h}$ and consequently having low-level $\alpha_{\nu} \beta_{3}$ integrin expression [66] were also used.

The conjugation of the FI moiety onto the G5 dendrimers, the counterstaining of the cell nuclei, and the red fluorescence of the encapsulated DOX drug enabled fluorescence microscopic imaging of the cellular uptake of the G5.NHAc-FI-PEG-RGD/DOX complexes (Figure 7). Untreated U87MG cells (Figure 7a) and U87MG cells treated with PBS (Figure 7b) only display the DAPI-related blue fluorescence of the cell nuclei. In sharp contrast, after $4 \mathrm{~h}$ incubation with the G5.NHAc-FI-PEG-RGD/DOX complexes, U87MG cells overexpressing $\alpha_{\nu} \beta_{3}$ integrin display significant red and green fluorescence signals (Figure 7c). These red and green fluorescence signals, 
which are associated with the FI-labeled G5 dendrimers and the encapsulated DOX drug, respectively, confirmed the specific internalization of the G5.NHAc-FI-PEG-RGD/DOX complexes into the cells. This can be further demonstrated by the purple signals in the merged images. In comparison, under similar microscopic conditions, the U87MG cells pre-blocked with free RGD only display faint red and green fluorescence signals (Figure 7d). These results suggest that the G5.NHAc-FI-PEG-RGD/DOX complexes are able to target integrin $\alpha_{\nu} \beta_{3}$-overexpressing cancer cells and can deliver DOX to the target cells via a receptor-mediated endocytosis pathway.

To prove our hypothesis that the G5.NHAc-FI-PEG-RGD/DOX complexes are able to specifically inhibit integrin $\alpha_{v} \beta_{3}$-overexpressing cancer cells, U87MG cells were incubated with the complexes for $4 \mathrm{~h}$. The medium in each well was then replaced with the same volume of fresh complete medium and the cells were incubated for an additional $48 \mathrm{~h}$ at $37^{\circ} \mathrm{C}$ before MTT assay (Figure 8). It can be seen that the treatment of U87MG cells with the G5.NHAc-FI-PEG-RGD/DOX complexes results in a significant decrease in the cell viability $(69.7 \pm 6.4 \%, \mathrm{p}<0.01$ versus the PBS control). In contrast, the integrin $\alpha_{\nu} \beta_{3}$-blocked U87MG cells have a viability of $96.5 \pm 5.1 \%$. Taken together with the above fluorescence microscopic observations, our results suggest that the G5.NHAc-FI-PEG-RGD/DOX complexes are able to exert specific therapeutic efficacy on integrin $\alpha_{\nu} \beta_{3}$-overexpressing cancer cells via a receptor-mediated endocytosis pathway.

\section{Conclusion}

In summary, multifunctional RGD-modified G5 dendrimers (G5.NHAc-FI-PEG-RGD) were synthesized and characterized for specific delivery of DOX to integrin $\alpha_{\nu} \beta_{3}$-overexpressing cancer cells. The relatively hydrophobic interior of the dendrimers enabled effective encapsulation of DOX. 
The formed G5.NHAc-FI-PEG-RGD/DOX complexes are stable and display a sustained drug release profile with higher release rate under physiological $\mathrm{pH}$ conditions than under acidic $\mathrm{pH}$ conditions, which can be correlated well with the NMR studies of the dendrimer host/ DOX guest interactions. Importantly, the formed G5.NHAc-FI-PEG-RGD/DOX complexes are able to specifically target cancer cells overexpressing $\alpha_{v} \beta_{3}$ integrins and display specific therapeutic efficacy to the target cells. The developed RGD-modified multifunctional dendrimer platform may hold great promise to be applied for targeting therapy of different types of $\alpha_{\nu} \beta_{3}$ integrin-overexpressing cancer cells.

\section{Acknowledgments}

This research was developed in the framework of the Master's degree (X. H.) on Nanochemistry and Nanomaterials from University of Madeira and financially supported by the FCT-Fundação para a Ciência e a Tecnologia (through the projects of PTDC/CTM-NAN/1748/2012, CQM pluriannual base funding of PEst-OE/QUI/UI0674/2011-2013, and the Portuguese NMR network PTNMR-2013), the Science and Technology Collaboration Fund between China and Hungary, Ministry of Science and Technology, and the National Natural Science Foundation of China (21273032). X. S. gratefully acknowledges the FCT and Santander bank for the Invited Chair in Nanotechnology. NMR experiments in University of Debrecen were financed by EU and the European Social Fund (ESF) under the project ENVIKUT (TÁMOP-4.2.2.A-11/1/KONV-2012-0043).

Supporting Information Available: Experimental section, part of results and discussion, and additional materials characterization and in vivo assay data. 


\section{References}

[1] D. Peer, J.M. Karp, S. Hong, O.C. Farokhzad, R. Margalit, R. Langer, Nanocarriers as an emerging platform for cancer therapy, Nat. Nanotechnol., 2 (2007) 751-760.

[2] Y. Wang, X. Cao, R. Guo, M. Shen, M. Zhang, M. Zhu, X. Shi, Targeted delivery of doxorubicin into cancer cells using a folic acid-dendrimer conjugate, Polym. Chem., 2 (2011) 1754-1760.

[3] Y. Wang, R. Guo, X. Cao, M. Shen, X. Shi, Encapsulation of 2-methoxyestradiol within multifunctional poly(amidoamine) dendrimers for targeted cancer therapy, Biomaterials, 32 (2011) $3322-3329$.

[4] J. Panyam, V. Labhasetwar, Biodegradable nanoparticles for drug and gene delivery to cells and tissue, Adv. Drug Deliv. Rev., 55 (2003) 329-347.

[5] T. Xiao, W. Hou, X. Cao, S. Wen, M. Shen, X. Shi, Dendrimer-entrapped gold nanoparticles modified with folic acid for targeted gene delivery applications, Biomater. Sci., 1 (2013) 1172-1180.

[6] Y. Shan, T. Luo, C. Peng, R. Sheng, A. Cao, X. Cao, M. Shen, R. Guo, H. Tomás, X. Shi, Gene delivery using dendrimer-entrapped gold nanoparticles as nonviral vectors, Biomaterials, 33 (2012) 3025-3035.

[7] D. Brambilla, J. Nicolas, B. Le Droumaguet, K. Andrieux, V. Marsaud, P.-O. Couraud, P. Couvreur, Design of fluorescently tagged poly(alkyl cyanoacrylate) nanoparticles for human brain endothelial cell imaging, Chem. Commun., 46 (2010) 2602-2604.

[8] H. Liu, Y. Xu, S. Wen, Q. Chen, L. Zheng, M. Shen, J. Zhao, G. Zhang, X. Shi, Targeted tumor computed tomography imaging using low-generation dendrimer-stabilized gold nanoparticles, Chem. Eur. J., 19 (2013) 6409-6416. 
[9] C. Peng, L. Zheng, Q. Chen, M. Shen, R. Guo, H. Wang, X. Cao, G. Zhang, X. Shi, PEGylated dendrimer-entrapped gold nanoparticles for in vivo blood pool and tumor imaging by computed tomography, Biomaterials, 33 (2012) 1107-1119.

[10] X. Shi, S.H. Wang, S.D. Swanson, S. Ge, Z. Cao, M.E. Van Antwerp, K.J. Landmark, J.R. Baker, Dendrimer-functionalized shell-crosslinked iron oxide nanoparticles for in-vivo magnetic resonance imaging of tumors, Adv. Mater., 20 (2008) 1671-1678.

[11] L. Zheng, J. Zhu, M. Shen, X. Chen, J.R. Baker, Jr., S.H. Wang, G. Zhang, X. Shi, Targeted cancer cell inhibition using multifunctional dendrimer-entrapped gold nanoparticles, Med. Chem. Commun., 4 (2013) 1001-1005.

[12] J. Zhu, L. Zheng, S. Wen, Y. Tang, M. Shen, G. Zhang, X. Shi, Targeted cancer theranostics using alpha-tocopheryl succinate-conjugated multifunctional dendrimer-entrapped gold nanoparticles, Biomaterials, 35 (2014) 7635-7646.

[13] Z. Zhou, B. Kong, C. Yu, X. Shi, M. Wang, W. Liu, Y. Sun, Y. Zhang, H. Yang, S. Yang, Tungsten Oxide Nanorods: An Efficient Nanoplatform for Tumor CT Imaging and Photothermal Therapy, Sci. Rep., 4 (2014) 3653.

[14] K. Li, S. Wang, S. Wen, Y. Tang, J. Li, X. Shi, Q. Zhao, Enhanced In Vivo Antitumor Efficacy of Doxorubicin Encapsulated within Laponite Nanodisks, ACS Appl. Mater. Interfaces, 6 (2014) 12328-12334.

[15] M. Zhang, R. Guo, Y. Wang, X. Cao, M. Shen, X. Shi, Multifunctional dendrimer/combretastatin A4 inclusion complexes enable in vitro targeted cancer therapy, Int. J. Nanomed., 6 (2011) 2337-2349.

[16] Y. Zheng, F. Fu, M. Zhang, M. Shen, M. Zhu, X. Shi, Multifunctional dendrimers modified with 
alpha-tocopheryl succinate for targeted cancer therapy, Med. Chem. Commun., 5 (2014) 879-885.

[17] T. Yih, M. Al- Fandi, Engineered nanoparticles as precise drug delivery systems, J. Cell. Biochem., 97 (2006) 1184-1190.

[18] C. Vauthier, C. Dubernet, C. Chauvierre, I. Brigger, P. Couvreur, Drug delivery to resistant tumors: the potential of poly(alkyl cyanoacrylate) nanoparticles, J. Controlled Release, 93 (2003) 151-160.

[19] D. Pan, C. Guo, K. Luo, Q. Yi, Z. Gu, PEGylated dendritic diaminocyclohexyl-platinum (II) conjugates as $\mathrm{pH}$-responsive drug delivery vehicles with enhanced tumor accumulation and antitumor efficacy, Biomaterials, 35 (2014) 10080-10092.

[20] W. She, N. Li, K. Luo, C. Guo, G. Wang, Y. Geng, Z. Gu, Dendronized heparin- doxorubicin conjugate based nanoparticle as pH-responsive drug delivery system for cancer therapy, Biomaterials, 34 (2013) 2252-2264.

[21] W. She, K. Luo, C. Zhang, G. Wang, Y. Geng, L. Li, B. He, Z. Gu, The potential of self-assembled, pH-responsive nanoparticles of mPEGylated peptide dendron-doxorubicin conjugates for cancer therapy, Biomaterials, 34 (2013) 1613-1623.

[22] S. Parveen, R. Misra, S.K. Sahoo, Nanoparticles: a boon to drug delivery, therapeutics, diagnostics and imaging, Nanomed.-Nanotechnol. Biol. Med., 8 (2012) 147-166.

[23] D. Tomalia, L. Reyna, S. Svenson, Dendrimers as multi-purpose nanodevices for oncology drug delivery and diagnostic imaging, Biochem. Soc. Trans., 35 (2007) 61-67.

[24] I.J. Majoros, T.P. Thomas, C.B. Mehta, J.R. Baker, Poly(amidoamine) dendrimer-based multifunctional engineered nanodevice for cancer therapy, J. Med. Chem., 48 (2005) 5892-5899.

[25] J. Zhu, X. Shi, Dendrimer-based nanodevices for targeted drug delivery applications, J. Mater. 
Chem. B, 1 (2013) 4199-4211.

[26] T.P. Thomas, I.J. Majoros, A. Kotlyar, J.F. Kukowska-Latallo, A. Bielinska, A. Myc, J.R. Baker, Targeting and inhibition of cell growth by an engineered dendritic nanodevice, J. Med. Chem., 48 (2005) 3729-3735.

[27] J.F. Kukowska-Latallo, K.A. Candido, Z. Cao, S.S. Nigavekar, I.J. Majoros, T.P. Thomas, L.P. Balogh, M.K. Khan, J.R. Baker, Nanoparticle targeting of anticancer drug improves therapeutic response in animal model of human epithelial cancer, Cancer Res., 65 (2005) 5317-5324.

[28] M.T. Morgan, Y. Nakanishi, D.J. Kroll, A.P. Griset, M.A. Carnahan, M. Wathier, N.H. Oberlies, G. Manikumar, M.C. Wani, M.W. Grinstaff, Dendrimer-encapsulated camptothecins: increased solubility, cellular uptake, and cellular retention affords enhanced anticancer activity in vitro, Cancer Res., 66 (2006) 11913-11921.

[29] R.S. Dhanikula, A. Argaw, J.-F. Bouchard, P. Hildgen, Methotrexate loaded polyether-copolyester dendrimers for the treatment of gliomas: enhanced efficacy and intratumoral transport capability, Mol. Pharmaceutics, 5 (2008) 105-116.

[30] X. Shi, S. Wang, S. Meshinchi, M.E. Van Antwerp, X. Bi, I. Lee, J.R. Baker, Dendrimer-entrapped gold nanoparticles as a platform for cancer-cell targeting and imaging, Small, 3 (2007) 1245-1252.

[31] I.J. Majoros, A. Myc, T. Thomas, C.B. Mehta, J.R. Baker, PAMAM dendrimer-based multifunctional conjugate for cancer therapy: synthesis, characterization, and functionality, Biomacromolecules, 7 (2006) 572-579.

[32] X. Shi, S.H. Wang, M. Shen, M.E. Antwerp, X. Chen, C. Li, E.J. Petersen, Q. Huang, W.J. Weber Jr, J.R. Baker Jr, Multifunctional dendrimer-modified multiwalled carbon nanotubes: 
synthesis, characterization, and in vitro cancer cell targeting and imaging, Biomacromolecules, 10 (2009) 1744-1750.

[33] X. Shi, T.P. Thomas, L.A. Myc, A. Kotlyar, J.R. Baker Jr, Synthesis, characterization, and intracellular uptake of carboxyl-terminated poly(amidoamine) dendrimer-stabilized iron oxide nanoparticles, Phys. Chem. Chem. Phys., 9 (2007) 5712-5720.

[34] H.-T. Chen, M.F. Neerman, A.R. Parrish, E.E. Simanek, Cytotoxicity, hemolysis, and acute in vivo toxicity of dendrimers based on melamine, candidate vehicles for drug delivery, J. Am. Chem. Soc., 126 (2004) 10044-10048.

[35] Y. Kim, A.M. Klutz, K.A. Jacobson, Systematic investigation of polyamidoamine dendrimers surface-modified with poly(ethylene glycol) for drug delivery applications: synthesis, characterization, and evaluation of cytotoxicity, Bioconjugate Chem., 19 (2008) 1660-1672.

[36] H. Liao, H. Liu, Y. Li, M. Zhang, H. Tomás, M. Shen, X. Shi, Antitumor efficacy of doxorubicin encapsulated within PEGylated poly(amidoamine) dendrimers, J. Appl. Polym. Sci., 131 (2014) 40358-40368.

[37] H. Liu, H. Wang, Y. Xu, M. Shen, J. Zhao, G. Zhang, X. Shi, Synthesis of PEGylated low generation dendrimer-entrapped gold nanoparticles for CT imaging applications, Nanoscale, 6 (2014) $4521-4526$.

[38] A.N. Gordon, J.T. Fleagle, D. Guthrie, D.E. Parkin, M.E. Gore, A.J. Lacave, Recurrent epithelial ovarian carcinoma: a randomized phase III study of pegylated liposomal doxorubicin versus topotecan, J. Clin. Oncol., 19 (2001) 3312-3322.

[39] D.L. Lamm, B.A. Blumenstein, E.D. Crawford, J.E. Montie, P. Scardino, H.B. Grossman, T.H. Stanisic, J.A. Smith Jr, J. Sullivan, M.F. Sarosdy, A randomized trial of intravesical doxorubicin and 
immunotherapy with bacille Calmette-Guerin for transitional-cell carcinoma of the bladder, N. Engl. J. Med., 325 (1991) 1205-1209.

[40] A. Santoro, T. Tursz, H. Mouridsen, J. Verweij, W. Steward, R. Somers, J. Buesa, P. Casali, D. Spooner, E. Rankin, Doxorubicin versus CYVADIC versus doxorubicin plus ifosfamide in first-line treatment of advanced soft tissue sarcomas: a randomized study of the European Organization for Research and Treatment of Cancer Soft Tissue and Bone Sarcoma Group, J. Clin. Oncol., 13 (1995) $1537-1545$.

[41] S. Zhu, M. Hong, G. Tang, L. Qian, J. Lin, Y. Jiang, Y. Pei, Partly PEGylated polyamidoamine dendrimer for tumor-selective targeting of doxorubicin: the effects of PEGylation degree and drug conjugation style, Biomaterials, 31 (2010) 1360-1371.

[42] M. Zhang, R. Guo, M. Kéri, I. Bányai, Y. Zheng, M. Cao, X. Cao, X. Shi, Impact of dendrimer surface functional groups on the release of doxorubicin from dendrimer carriers, J. Phys. Chem. B, 118 (2014) 1696-1706.

[43] S.K. Choi, T. Thomas, M.-H. Li, A. Kotlyar, A. Desai, J.R. Baker, Jr., Light-controlled release of caged doxorubicin from folate receptor-targeting PAMAM dendrimer nanoconjugate, Chem. Commun., 46 (2010) 2632-2634.

[44] N. Li, N. Li, Q. Yi, K. Luo, C. Guo, D. Pan, Z. Gu, Amphiphilic peptide dendritic copolymer-doxorubicin nanoscale conjugate self-assembled to enzyme-responsive anti-cancer agent, Biomaterials, 35 (2014) 9529-9545.

[45] C. Zhang, D. Pan, K. Luo, N. Li, C. Guo, X. Zheng, Z. Gu, Dendrimer-doxorubicin conjugate as enzyme-sensitive and polymeric nanoscale drug delivery vehicle for ovarian cancer therapy, Polym. Chem., 5 (2014) 5227-5235. 
[46] C. Zhang, D. Pan, K. Luo, W. She, C. Guo, Y. Yang, Z. Gu, Peptide Dendrimer- Doxorubicin Conjugate- Based Nanoparticle as an Enzyme- Responsive Drug Delivery System for Cancer Therapy, Adv. Healthcare Mater., 3 (2014) 1299-1308.

[47] D. Bhadra, S. Bhadra, S. Jain, N. Jain, A PEGylated dendritic nanoparticulate carrier of fluorouracil, Int. J. Pharm., 257 (2003) 111-124.

[48] X. Shi, I. Lee, X. Chen, M. Shen, S. Xiao, M. Zhu, J.R. Baker, S.H. Wang, Influence of dendrimer surface charge on the bioactivity of 2-methoxyestradiol complexed with dendrimers, Soft Matter, 6 (2010) 2539-2545.

[49] A. D'Emanuele, D. Attwood, Dendrimer-drug interactions, Adv. Drug Deliv. Rev., 57 (2005) 2147-2162.

[50] H.-J. Cho, I.-S. Yoon, H.Y. Yoon, H. Koo, Y.-J. Jin, S.-H. Ko, J.-S. Shim, K. Kim, I.C. Kwon, D.-D. Kim, Polyethylene glycol-conjugated hyaluronic acid-ceramide self-assembled nanoparticles for targeted delivery of doxorubicin, Biomaterials, 33 (2012) 1190-1200.

[51] R.F. Barth, D.M. Adams, A.H. Soloway, F. Alam, M.V. Darby, Boronated starburst dendrimer-monoclonal antibody immunoconjugates: evaluation as a potential delivery system for neutron capture therapy, Bioconjugate Chem., 5 (1994) 58-66.

[52] I. Dijkgraaf, A.Y. Rijnders, A. Soede, A.C. Dechesne, G.W. van Esse, A.J. Brouwer, F.H. Corstens, O.C. Boerman, D.T. Rijkers, R.M. Liskamp, Synthesis of DOTA-conjugated multivalent cyclic-RGD peptide dendrimers via 1, 3-dipolar cycloaddition and their biological evaluation: implications for tumor targeting and tumor imaging purposes, Org. Biomol. Chem., 5 (2007) 935-944.

[53] L. Han, R. Huang, J. Li, S. Liu, S. Huang, C. Jiang, Plasmid pORF-hTRAIL and doxorubicin 
co-delivery targeting to tumor using peptide-conjugated polyamidoamine dendrimer, Biomaterials, $32(2011)$ 1242-1252.

[54] E. Hill, R. Shukla, S.S. Park, J.R. Baker, Jr., Synthetic PAMAM-RGD conjugates target and bind To odontoblast-like MDPC 23 cells and the predentin in tooth organ cultures, Bioconjugate Chem., 18 (2007) 1756-1762.

[55] R. Shukla, E. Hill, X. Shi, J. Kim, M.C. Muniz, K. Sun, J.R. Baker, Jr., Tumor microvasculature targeting with dendrimer-entrapped gold nanoparticles, Soft Matter, 4 (2008) 2160-2163.

[56] S. Zhu, L. Qian, M. Hong, L. Zhang, Y. Pei, Y. Jiang, RGD-modified PEG-PAMAM-DOX conjugate: in vitro and in vivo targeting to both tumor neovascular endothelial cells and tumor cells, Adv. Mater., 23 (2011) H84-H89.

[57] D. Pandita, J.L. Santos, J. Rodrigues, A.P. Pêgo, P.L. Granja, H. Tomás, Gene delivery into mesenchymal stem cells: a biomimetic approach using RGD nanoclusters based on poly(amidoamine) dendrimers, Biomacromolecules, 12 (2011) 472-481.

[58] J.L. Santos, H. Oliveira, D. Pandita, J. Rodrigues, A.P. Pêgo, P.L. Granja, H. Tomás, Functionalization of poly(amidoamine) dendrimers with hydrophobic chains for improved gene delivery in mesenchymal stem cells, J. Controlled Release, 144 (2010) 55-64.

[59] N. Nasongkla, X. Shuai, H. Ai, B.D. Weinberg, J. Pink, D.A. Boothman, J. Gao, cRGD-functionalized polymer micelles for targeted doxorubicin delivery, Angew. Chem. Int. Ed., 116 (2004) 6483-6487.

[60] Q. Chen, K. Li, S. Wen, H. Liu, C. Peng, H. Cai, M. Shen, G. Zhang, X. Shi, Targeted CT/MR dual mode imaging of tumors using multifunctional dendrimer-entrapped gold nanoparticles, Biomaterials, 34 (2013) 5200-5209. 
[61] H. Liu, H. Wang, Y. Xu, R. Guo, S. Wen, Y. Huang, W. Liu, M. Shen, J. Zhao, G. Zhang, X. Shi, Lactobionic acid-modified dendrimer-entrapped gold nanoparticles for targeted computed tomography imaging of human hepatocellular carcinoma, ACS Appl. Mater. Interfaces, 6 (2014) 6944-6953.

[62] R. Shukla, T.P. Thomas, J. Peters, A. Kotlyar, A. Myc, J. James R. Baker, Tumor angiogenic vasculature targeting with PAMAM dendrimer-RGD conjugates, Chem. Commun., (2005) $5739-5741$.

[63] D. Cakara, J. Kleimann, M. Borkovec, Microscopic protonation equilibria of poly(amidoamine) dendrimers from macroscopic titrations, Macromolecules, 36 (2003) 4201-4207.

[64] J. Hu, Y. Cheng, Q. Wu, L. Zhao, T. Xu, Host-Guest chemistry of dendrimer-drug complexes. 2. Effects of molecular properties of guests and surface functionalities of dendrimers, J. Phys. Chem. B, 113 (2009) 10650-10659.

[65] W. Chen, D.A. Tomalia, J.L. Thomas, Unusual pH-dependent polarity changes in PAMAM dendrimers: evidence for pH-responsive conformational changes, Macromolecules, 33 (2000) 9169-9172.

[66] S.-H. Cheng, C.-H. Lee, M.-C. Chen, J.S. Souris, F.-G. Tseng, C.-S. Yang, C.-Y. Mou, C.-T. Chen, L.-W. Lo, Tri-functionalization of mesoporous silica nanoparticles for comprehensive cancer theranostics-the trio of imaging, targeting and therapy, J. Mater. Chem., 20 (2010) 6149-6157. 


\section{Figure captions}

Figure 1. Schematic representation of the preparation of HOOC-PEG-RGD and G5.NHAc-FI-PEG-RGD/DOX complexes.

Figure 2. ${ }^{1} \mathrm{H}$ NMR spectrum of G5.NHAc-FI-PEG-RGD in $\mathrm{D}_{2} \mathrm{O}$. Molecular structures of PEG, dendrimer backbone, FI, and RGD are also shown.

Figure 3. UV-vis spectra of free DOX dissolved in ethanol, the G5.NHAc-FI-PEG-RGD dendrimers dissolved in water, and the G5.NHAc-FI-PEG-RGD/DOX complexes dissolved in water.

Figure 4. Cumulative release of DOX from the G5.NHAc-FI-PEG-RGD/DOX complexes in PBS $(\mathrm{pH}=7.4)$ and acetate buffer $(\mathrm{pH}=5.0)$ at $37^{\circ} \mathrm{C}$. Free DOX dissolved in ethanol and released in PBS $(\mathrm{pH}=7.4)$ was used as a control. The data were expressed as mean $=$ S.D. $(n=3)$.

Figure 5. ${ }^{1} \mathrm{H}$ NMR spectra of G5.NHAc-FI-PEG-RGD/DOX at pH 5.0 (a) and pH 7.0 (b). ${ }^{1} \mathrm{H}$ NMR spectrum of free $\mathrm{DOX} \cdot \mathrm{HCl}$ with its self-pH is also shown (c). All samples were dissolved in $\mathrm{D}_{2} \mathrm{O}$. The DOX concentration in each group was set at $5 \mathrm{mg} / \mathrm{mL}$.

Figure 6. MTT assay of the viability of U87MG cells after treatment with $10 \mu \mathrm{L}$ PBS (control), free $\mathrm{DOX} \cdot \mathrm{HCl}$ dissolved in $10 \mu \mathrm{L}$ PBS $(5 \mu \mathrm{M})$, the G5.NHAc-FI-PEG-RGD/DOX complexes with a DOX concentration of $5 \mu \mathrm{M}$, and the DOX-free G5. NHAc-FI-PEG-RGD dendrimers at the equivalent dendrimer concentration.

Figure 7. Fluorescence microscopy images of U87MG cells treated with EMEM medium (a), PBS (b), the G5.NHAc-FI-PEG-RGD/DOX complexes only (c), and $2 \mu \mathrm{M}$ RGD for $1 \mathrm{~h}$ followed by the G5.NHAc-FI-PEG-RGD/DOX complexes for $4 \mathrm{~h}(\mathrm{~d})$. In all cases, the DOX concentration was kept at $5 \mu \mathrm{M}$. For each panel, the images from left to right show the bright field, the blue fluorescence channel detecting the DAPI dye, the red fluorescence channel detecting DOX, the green 
fluorescence channel detecting the FI, and the merged images of the above three modes. All the images were collected under similar instrumental conditions.

Figure 8. MTT viability assay of U87MG cells after $4 \mathrm{~h}$ treatment with $10 \mu \mathrm{L}$ PBS buffer or the G5.NHAc-FI-PEG-RGD/DOX complexes $\quad([\mathrm{DOX}]=5 \mu \mathrm{M})$, followed by replacing with DOX-free fresh complete medium and incubation for $48 \mathrm{~h}$. U87MG cells with $\alpha_{\nu} \beta_{3}$ integrin-blocked via pre-incubation with free $\operatorname{RGD}(2 \mu \mathrm{M})$ for $1 \mathrm{~h}$ were also tested for comparison. The data are expressed as mean \pm S.D. $(n=4)$. 

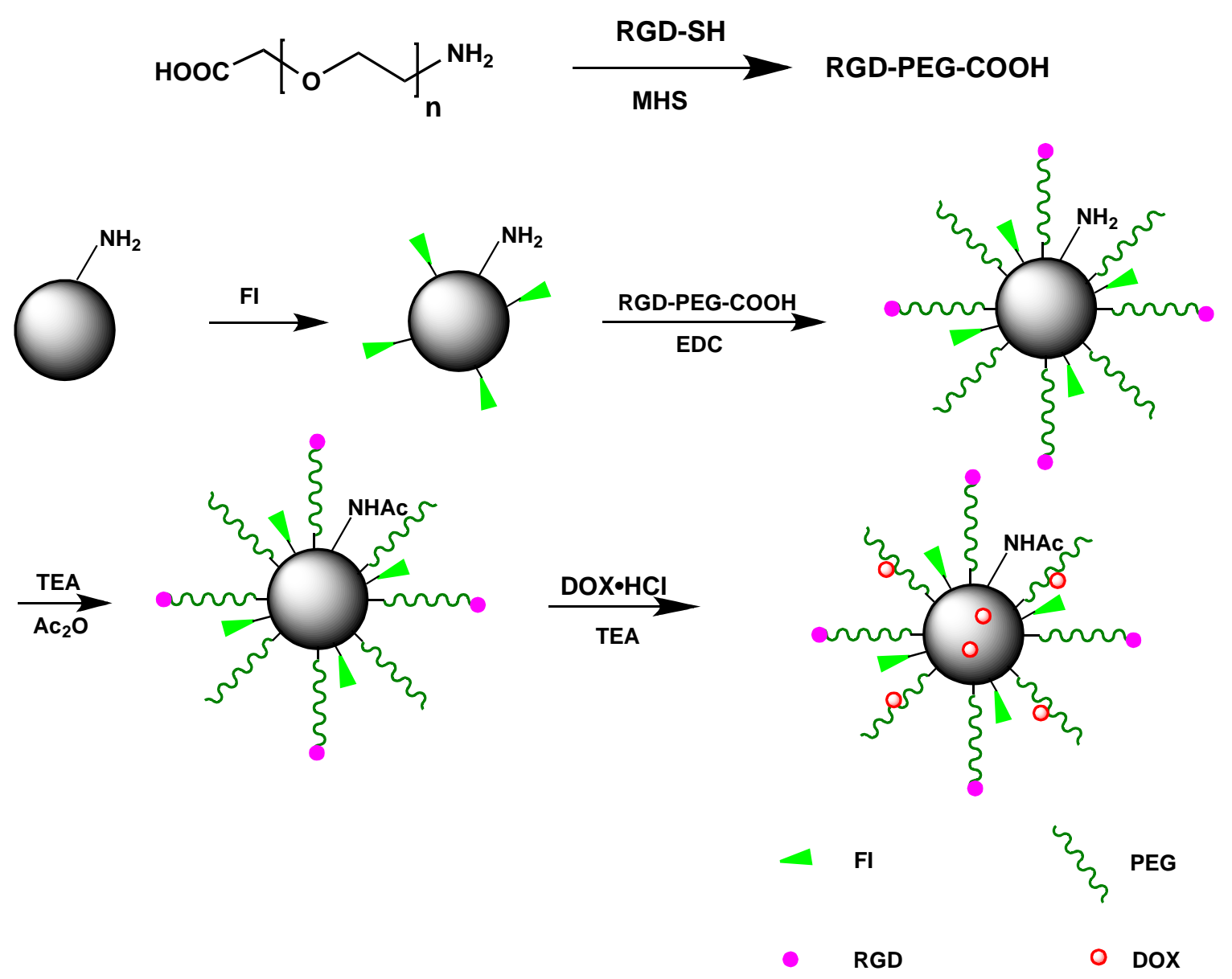

Figure 1

He et al. 


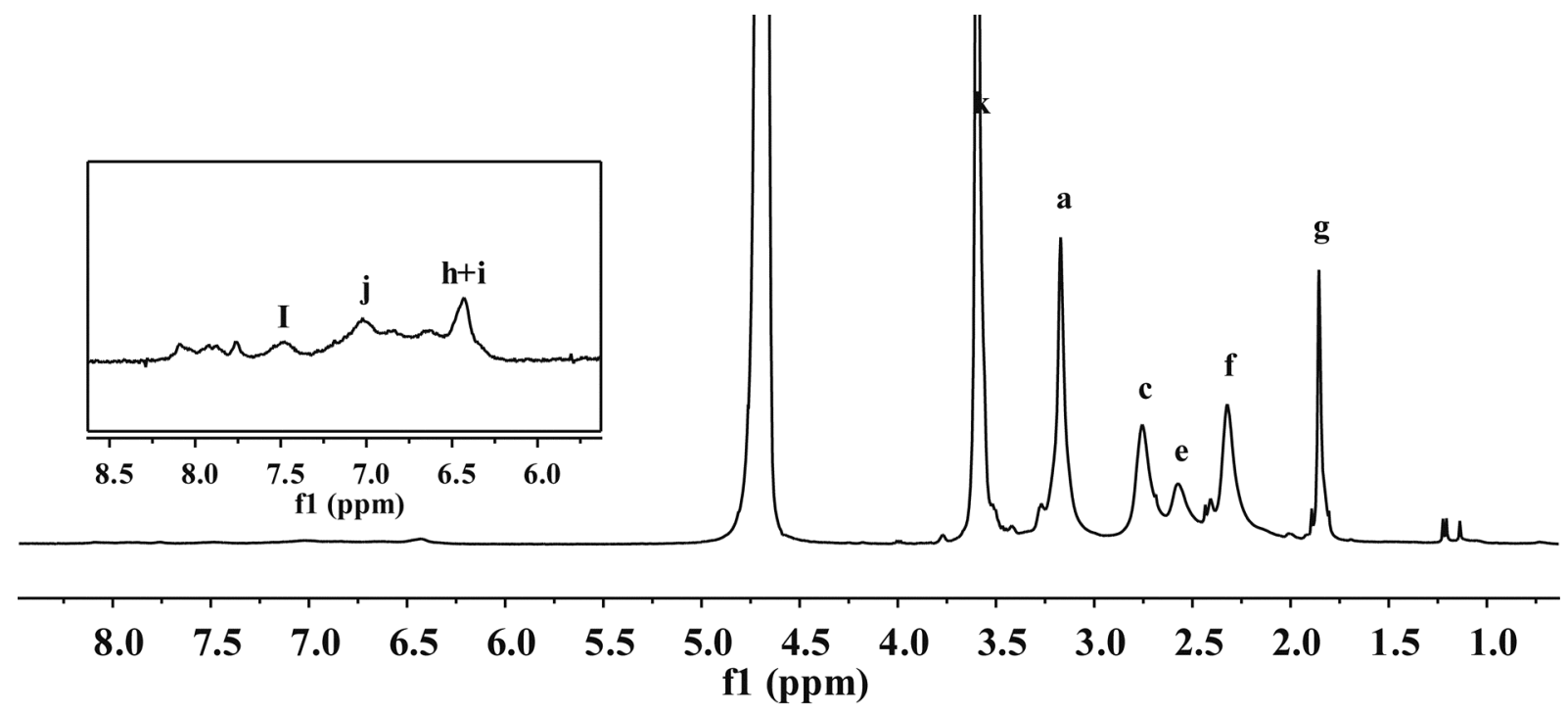

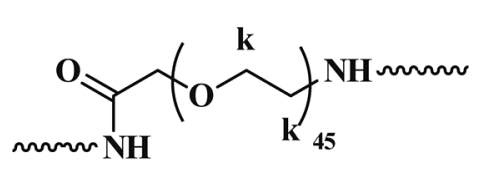

PEG

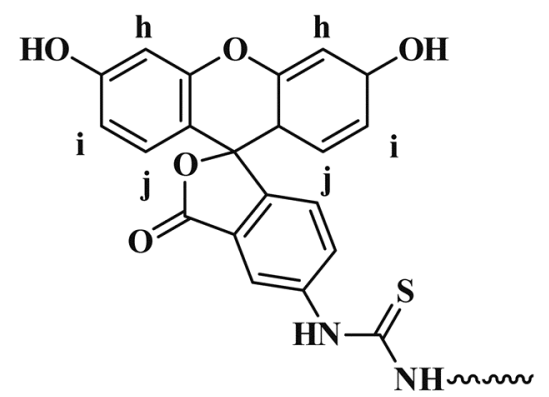

FI

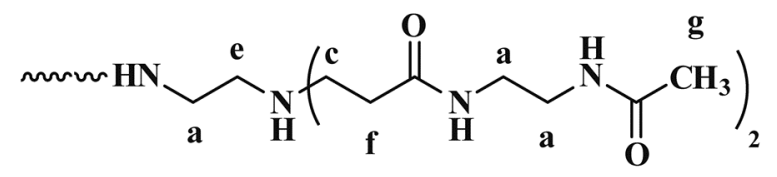

Dendrimer

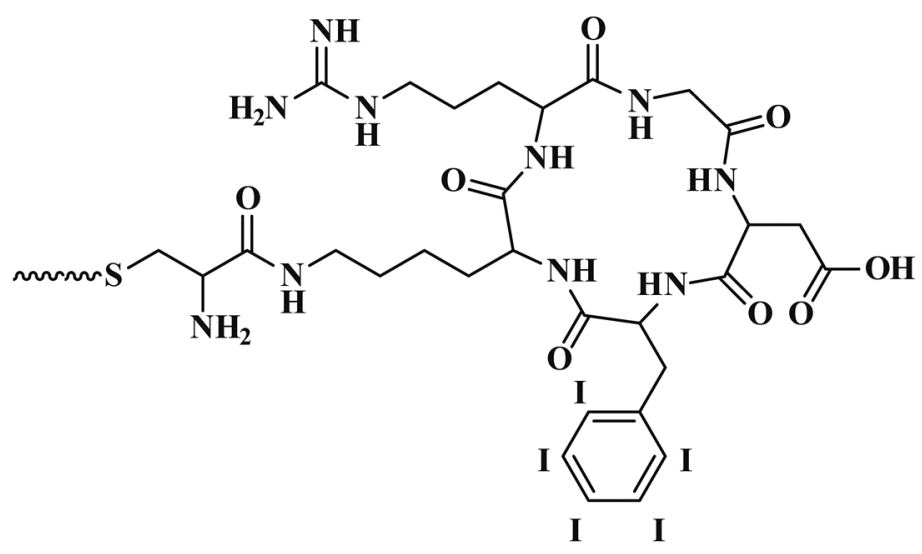

RGD

Figure 2

He et al. 


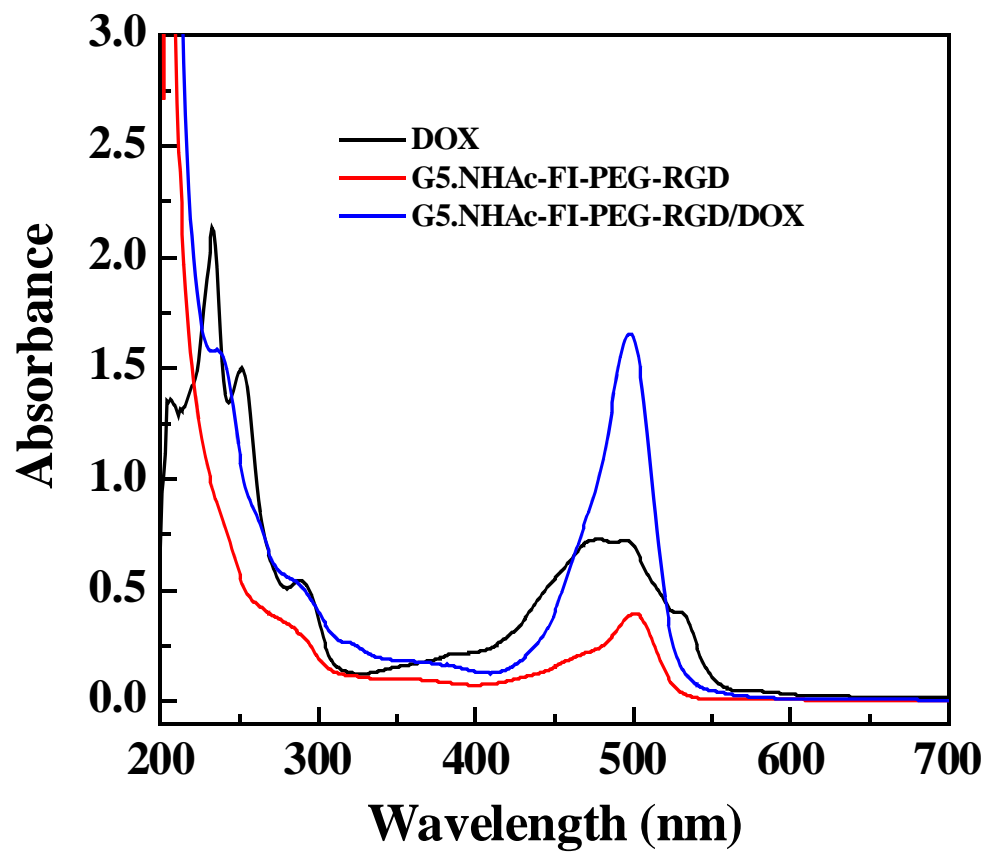

Figure 3

He et al. 


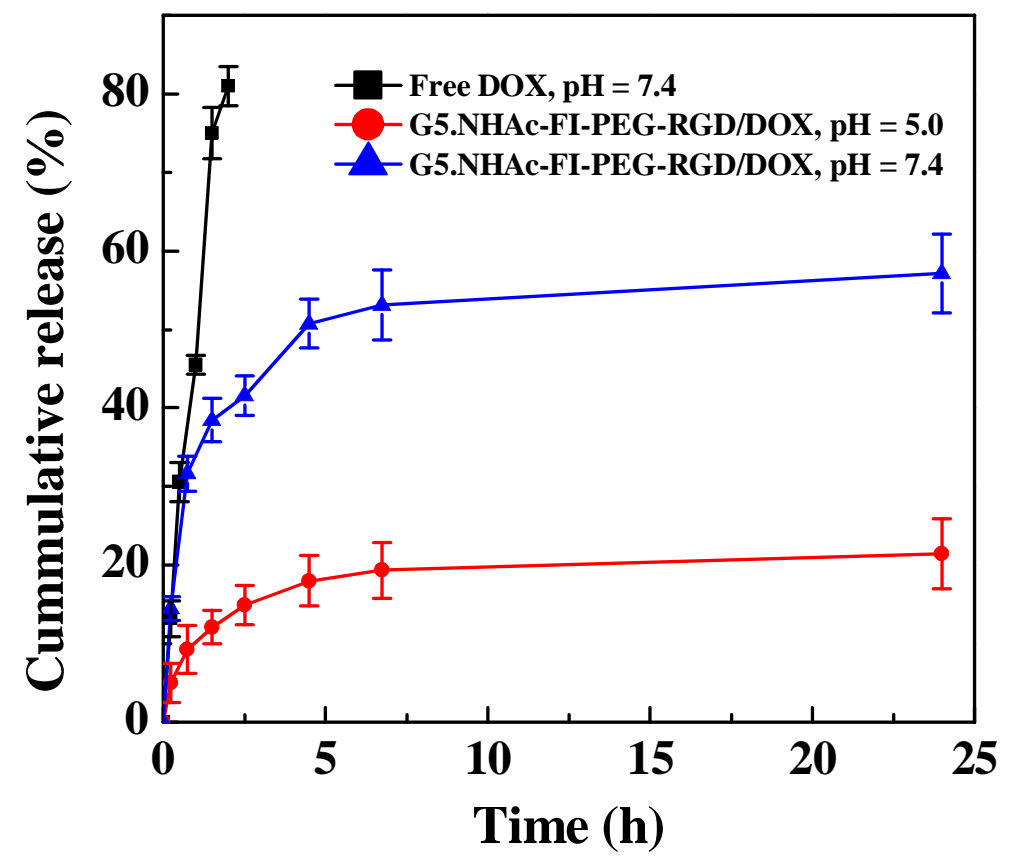

Figure 4

He et al. 

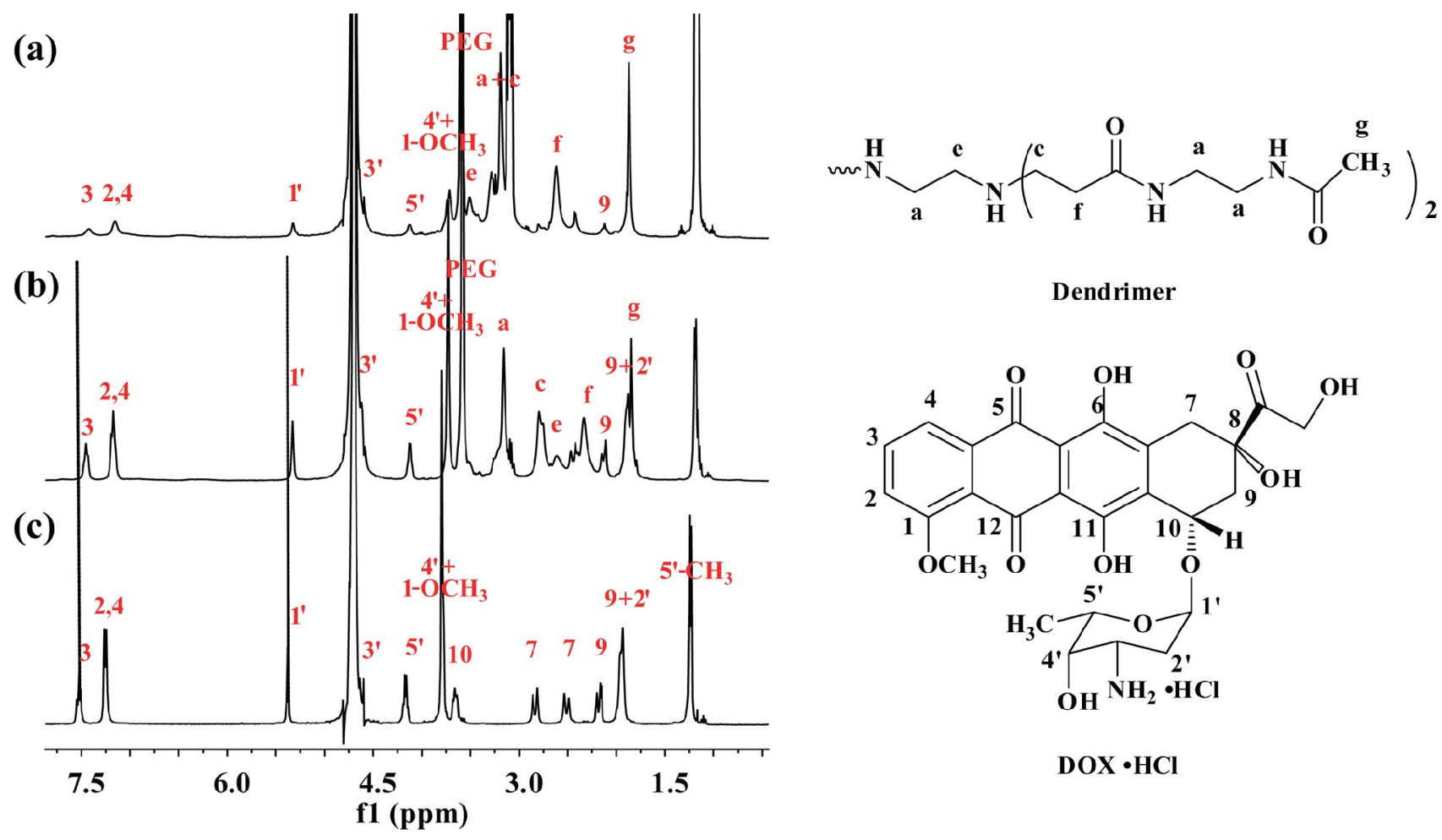

Dendrimer

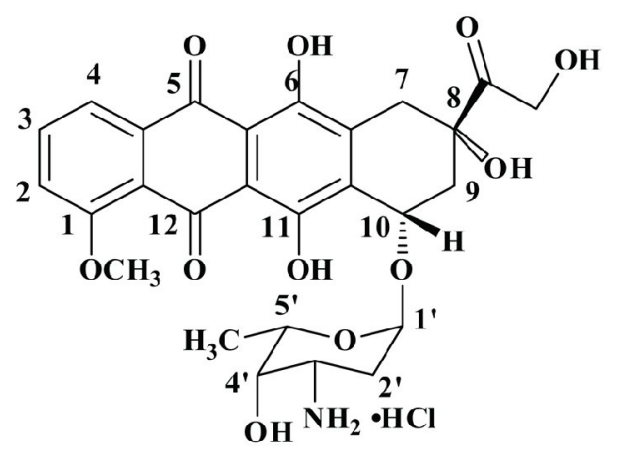

DOX $\bullet H C l$

Figure 5

He et al. 


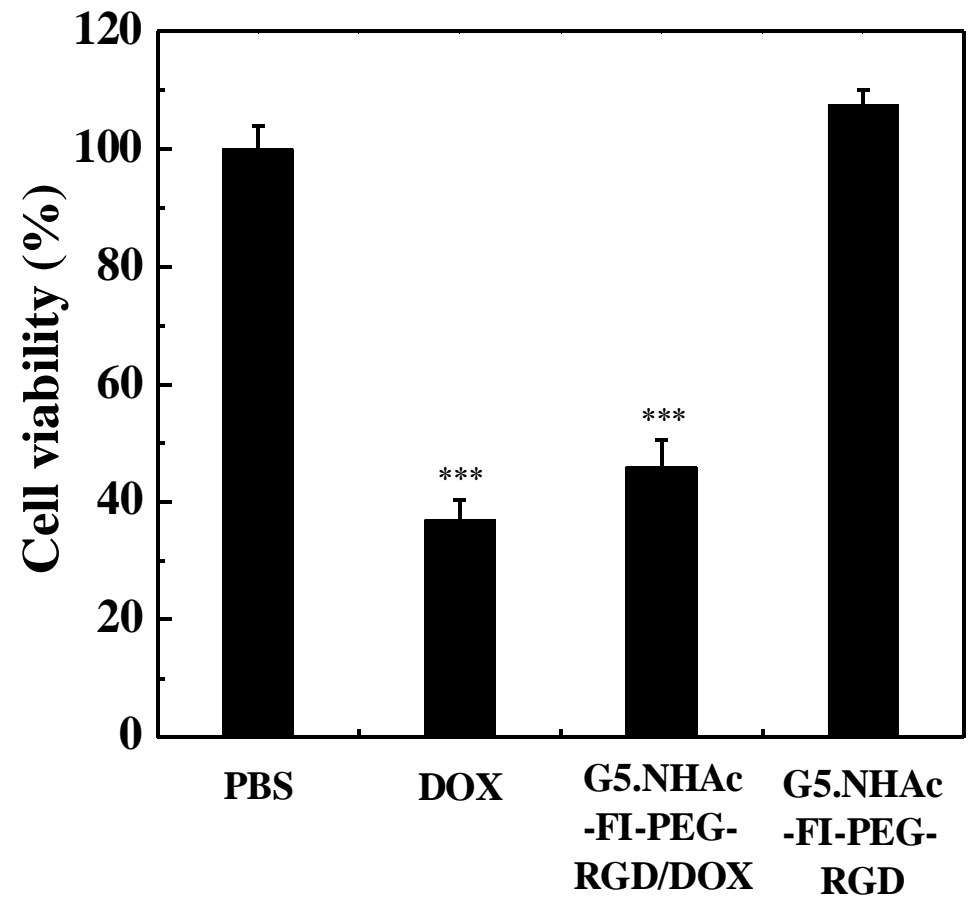

Figure 6

He et al. 


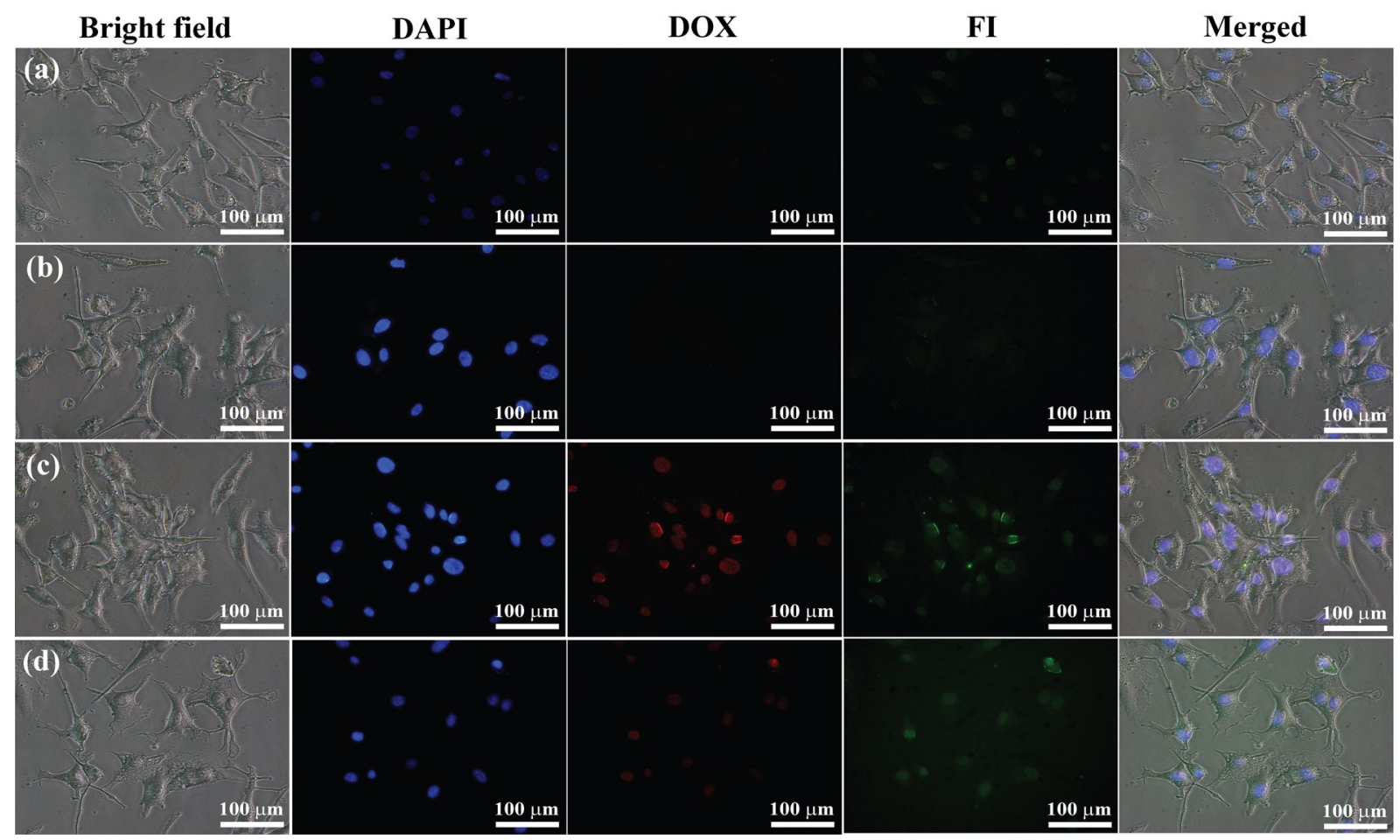

Figure 7

He et al. 


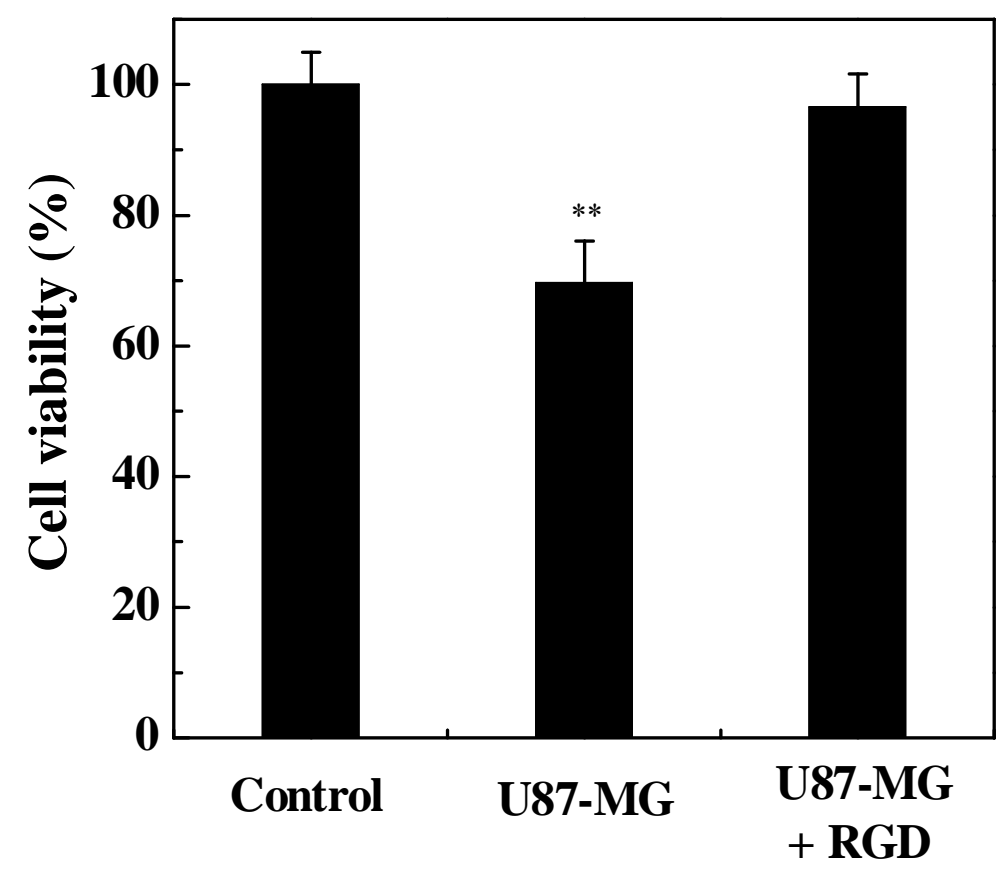

Figure 8

He et al. 

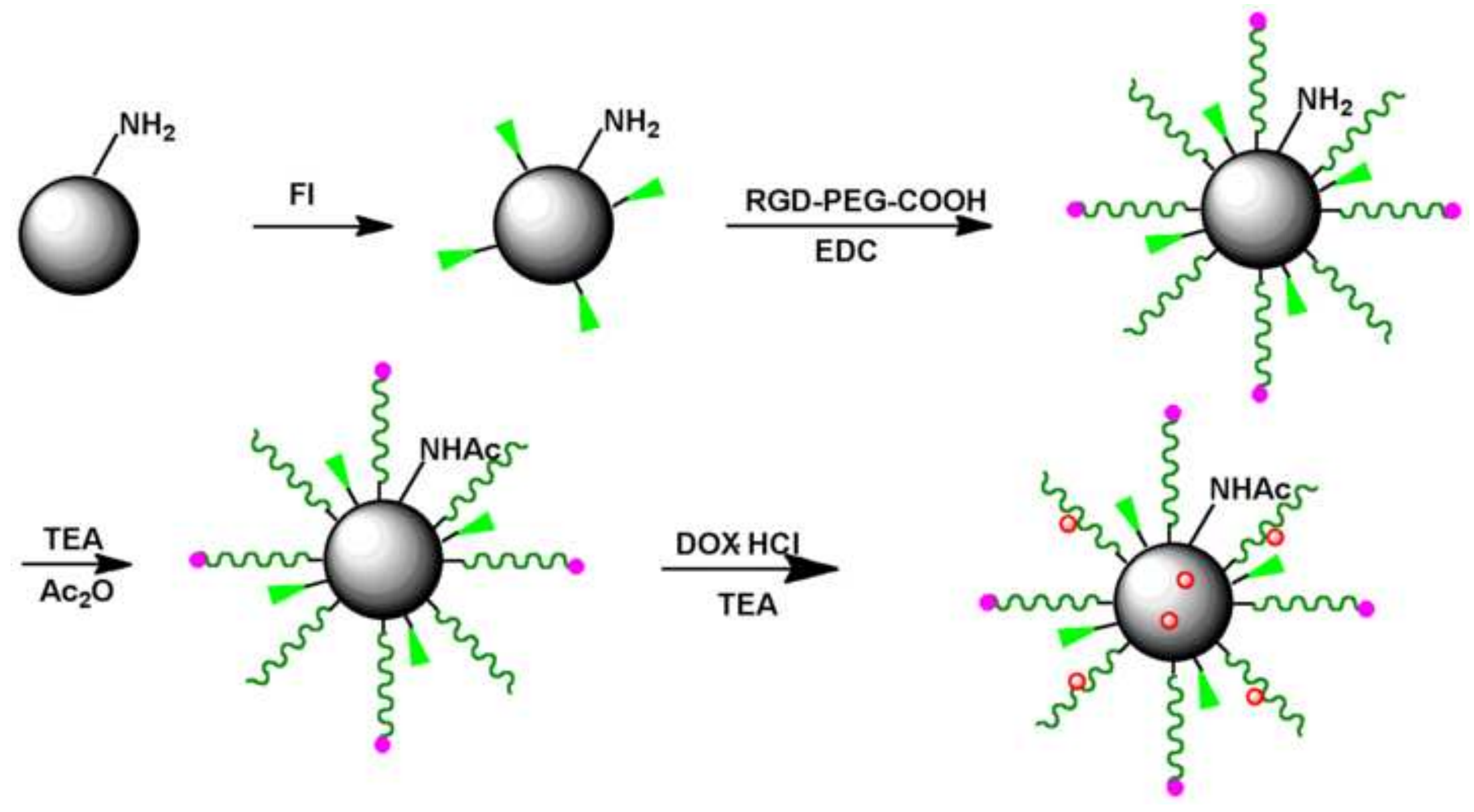

DOX HCI

TEA

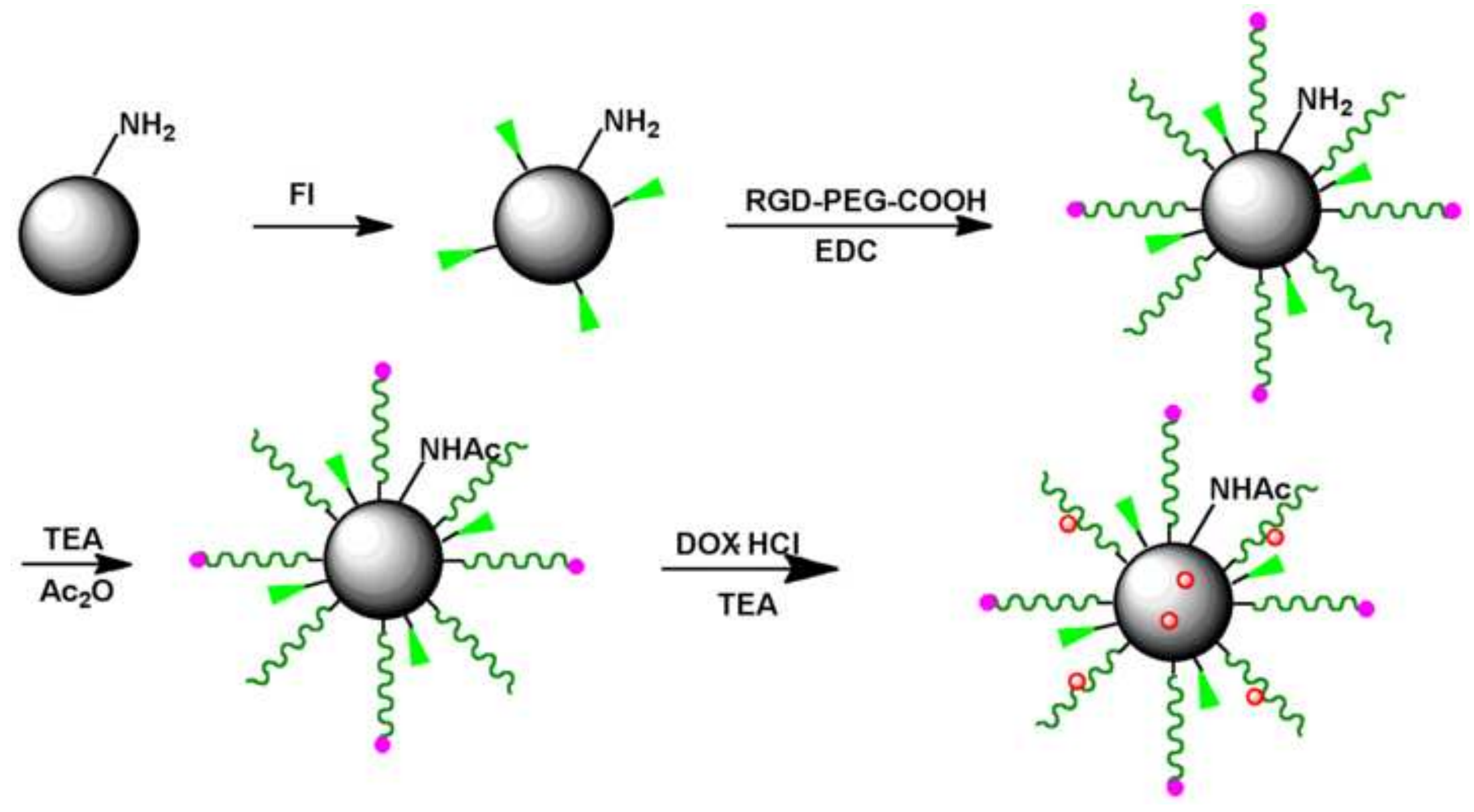

